\title{
USO DO PROBIÓTICO BACSOL-VT EM FRANGOS DE CORTE DE LINHAGEM COLONIAL CRIADOS EM CONFINAMENTO
}

\author{
CALIMAN, Ana Paula Melo ${ }^{1}$ \\ COUTO, Leomam Almeida ${ }^{2}$
}

Recebido em: 2010.09.09 Aprovado em: 2010.10.25

ISSUE DOI: $10.3738 / 1982.2278-465$

RESUMO: O presente trabalho, realizado no Campus da FAFRAM (Faculdade Dr. Francisco Maeda) em Ituverava (SP), objetivou avaliar a influencia do probiótico BACSOL-VT na concentração de 0,03\% ( $300 \mathrm{~g} /$ Tonelada) e $0,05 \%$ ( $500 \mathrm{~g} /$ Tonelada) na ração, sobre o desenvolvimento de frangos de corte de linhagem colonial. Foram usados 3 tratamentos com 2 repetições, com 12 aves por repetição. Os resultados mostraram que o uso do probiótico não influenciou significativamente o ganho de peso dos frangos. Entretanto, a conversão alimentar dos animais foi influenciada pelo uso do probiótico, sendo de 2,14:1 no tratamento testemunha e de 2,06:1 e de 2,05:1 nos tratamentos com 0,03\% e 0,05\% de probiótico, respectivamente. A taxa de mortalidade dos animais foi de $1,4 \%$. O custo de produção foi estimado em R $\$ 1,88$ (Um real e oitenta e oito centavos) por quilograma de peso vivo de frango.

Palavras-chave: Frango colonial. Probiótico. Conversão alimentar.

\section{USE OF PROBIOTIC BACSOL-VT IN BROILER STRAIN OF COLONIAL RAISED IN CONFINEMENT}

SUMMARY: The experiment was realized in the FAFRAM Campus (Faculdade Dr Francisco Maeda) at Ituverava (SP) aiming to evaluate the influence of the BACSOL-VT probiotic in concentrations of $0,03 \%$ (300g/Tonelada) and $0,05 \%$ " $(500 \mathrm{~g} /$ Tonelada) on the ration, on the growth of broiler chicken of colonial breed. Three treatments were used, with 2 repetitions, using 12 animals in each repetition. Results show that the use of the probiotic did not significantly influenced the weight gain of the chicken. However, feeding conversion of the animals was influenced by the use of the probiotic, being of 2,14:1 on the base treatment and of 2,06:1 and $2,05: 1$ on the treatments using $0,03 \%$ and $0,05 \%$ of probiotic, respectively. The death rate of the animals was of $1,4 \%$. Production cost was of $\mathrm{R} \$ 1,88$ (One Brazilian real and eighty eight cents) per kilogram of chicken.

Keywords: Colonial chicken. Probiotic. Feeding of chicken.

\section{INTRODUÇÃO}

A Avicultura brasileira, é exemplo de atividade agrícola e cadeia produtiva de sucesso. A utilização de modernos sistemas de planejamento, organização, coordenação dos elos, ágil incorporação de novas tecnologias e técnicas gerencias, enfim, trabalho competente de todos os segmentos, reflete-se no extraordinário e constante crescimento da produção avícola

\footnotetext{
${ }^{1}$ Medica Veterinária. FE/FAFRAM. Ituverava

${ }^{2}$ Zootecnista. Prof. Dr. dos cursos de Agronomia e Medicina Veterinária. FE/FAFRAM. Ituverava
} 
industrial.

O Brasil, apesar de ter iniciado a sua produção num período mais recente, na década de 70 , já ocupa a $3^{\circ}$ posição mundial entre os produtores de aves de corte.

Os Estados Unidos, a China e o Brasil são responsáveis por cerca de 56\% da produção mundial de carne de aves que em 2008 chegou a 71 milhões de Toneladas. Em 2008, o Brasil produziu 11,1 milhões de toneladas de carne de frango. As exportações brasileiras foram de 3,215 milhões de Toneladas, o que coloca o Brasil como o maior exportador mundial de carne de frango (ANUALPEC, 2008).

Figueiredo et al. (2001) classificam os sistemas de produção avícola brasileiros da seguinte maneira: Avicultura industrial, Avicultura Nativa e Avicultura Caipira ou Colonial. A avicultura industrial é a mais conhecida e é altamente tecnificada. A Avicultura Nativa é conhecida como sistema nativo brasileiro, onde as galinhas se reproduzem de forma natural via choco. As aves apresentam resistência às principais doenças e quase nunca são vacinadas nem vermifugadas. Recebem apenas suplementação alimentar com grãos, ração, verduras, etc. e apresentam baixa velocidade de crescimento. Os machos são abatidos após seis meses de idade com aproximadamente $1,5 \mathrm{~kg}$ e as fêmeas são mantidas para produção de cerca de 100 ovos/ave/ano, destinados ao consumo e/ou ninhada.

A avicultura caipira ou colonial, caracterizada como o tipo de criação em que os pintos, resultantes do cruzamento de raças pesadas de corte com raças semi pesadas de postura, são produzidos em incubatórios e são comercializados, já vacinados contra as doenças de Marek e Bouba Aviária. A criação das aves é feita de forma intensiva ou semi intensivas com acesso a áreas de pastejo, onde consomem sementes, capins, insetos e também ração. Esse sistema, denominado Free Range Chicken, teve sua origem na Europa e nos Estados Unidos. Segundo Lana (2001), chegou ao Brasil em 1980, com a introdução da linhagem de galinha caipira francesa Label Rouge. Atualmente representa pouco mais de $1 \%$ do mercado avícola, com crescimento continuo desde a década de 1990 (DEMATTÊ FILHO; MENDES, 2001). Muniz (2001) explica que o frango caipira/colonial não é uma novidade no mercado, mas sim uma modalidade antiga de criação de aves, obviamente com correções conceituais. O sistema organizacional contempla a produção dirigida no campo da sanidade, genética, nutrição e gerenciamento como negócio.

A cadeia produtiva da avicultura modernizou-se ultimamente em função da necessidade de redução de custos, aumento da produtividade e produção de alimento de qualidade. Isso tem atraído investimentos em tecnologias e manejo objetivando produzir um frango de qualidade num menor espaço de tempo possível (ÁVILA, et al. 1998). 
Para que o país tenha uma avicultura competitiva e crescente, tanto no mercado interno como no externo é necessário que as empresas do setor Agro-Industrial tenham um adequado sistema de biossegurança, com regras bem definidas em relação ao manejo e controle sanitário, minimizando o uso de antimicrobianos.

Por isso empresas vêm investindo na utilização de promotores de crescimento, como os probióticos que são organismos vivos que, ingeridos exercem efeitos benéficos na flora bacteriana intestinal do hospedeiro. Ainda os probióticos têm efeito sobre o equilíbrio bacteriano intestinal, controle do colesterol e de diarréias, melhorando o desenvolvimento das aves (ANDREATTI FILHO, 2006).

Esse fato mantém atrativo o modelo de produção de aves que, apesar de melhoradas, mantém características de aves rústicas, podendo ser criadas em sistemas abertos (terreiros), semi confinados ou confinados, oferecendo aos brasileiros, a possibilidade de manter o hábito saudosista de consumir carne de animais criados nas condições "caipiras", especialmente de frangos (FIGUEIREDO; ÁVILA, 2001). Esse modelo de criação carece de informações quanto ao uso de substâncias que possam melhorar os índices de produtividade, sem onerar demais os custos de produção.

Nesse sentido, o uso de probióticos tem se mostrado eficiente em vários estudos na avicultura comercial de corte e também de postura (ANDREATTI FILHO, 2006).

Esse trabalho objetiva avaliar o uso do probiótico comercial no desempenho produtivo de frangos de linhagem colonial criados em confinamento.

\section{MATERIAL E MÉTODOS}

O trabalho foi realizado no campus da Faculdade Dr. Francisco Maeda-FAFRAMItuverava-SP,entre os meses de Janeiro e Março de 2009, num período experimental de 85 dias.

As aves foram criadas em um pequeno galpão de alvenaria, de duas águas, coberto com telhas de barro, com as paredes laterais protegidas por tela metálica, com dimensões de 6 metros de comprimento por 2 metros de largura, o qual foi lavado e esterilizado, recebendo uma caiação em todas as paredes internas e no piso, antes de receber as aves.

Internamente, o espaço foi dividido em 6 boxes de $1 \mathrm{~m}$ x 1,5m (1,5m2). A divisão foi feita com bambu na parte frontal, onde se instalou uma porta de acesso aos boxes e tela de galinheiro sobre tábuas nas laterais. Cada boxe recebeu cama de frango, constituída de maravalha, com $12 \mathrm{~cm}$ de altura; iluminação feita com uma lâmpada de 40 watts, que serviu 
também como aquecedor nos primeiros 15 dias; um bebedouro tipo copo de pressão invertido com capacidade para 3,6 litros de água e um comedouro cilíndrico com capacidade para 5kg de ração (Figura 1).

Foram utilizadas 72 aves da linhagem de frangos caipira de origem francesa denominada "Label Rouge Pescoço Pelado", divididas aleatoriamente, em 6 lotes de 12 aves cada um, numa densidade de 8 aves/m2. Cada lote foi alojado em 1 boxe numerado, distribuído em um Delineamento Inteiramente Casualizado (DIC), com 3 tratamentos e 2 repetições, com cada ave representando uma parcela.

Os tratamentos utilizados, constaram do seguinte:

Tratamento1 (T1) - As Aves receberam ração caseira ad libitum, sem nenhum acréscimo de probiótico (Testemunha).

Tratamento 2 (T2) - As Aves receberam ração caseira ad libitum, acrescida do probiótico BACSOL - VT na concentração de 300g/Tonelada de ração $(0,03 \%)$.

Tratamento 3 (T3) - As Aves receberam ração caseira ad libitum, acrescida do probiótico BACSOL - VT na concentração de 500g/Tonelada de ração $(0,05 \%)$.

A ração "caseira" fornecida durante todo o período experimental foi formulada com $68,6 \%$ de milho moído, 27,4\% de farelo de soja e $4 \%$ de núcleo especifico para cada idade (núcleo inicial 0 a 36 dias; núcleo crescimento 37 a 66 dias e núcleo terminação 67 a 84 dias), com teor protéico estimado de $19,0 \%$.

Após o $30^{\circ}$ dia de criação todos os tratamentos receberam, diariamente, um molho de capim Tifton 85 (Cynodon dactylon) verde, que era amarrado à altura das aves, no centro do boxe, ficando à disposição das aves. (Figura 2).

A Avaliação do desenvolvimento das aves em cada tratamento foi feita através de pesagens no $1^{\circ}, 16^{\circ}, 31^{\circ}, 43^{\circ}, 74^{\circ}$ e $84^{\circ}$ dias do período experimental, registrando-se os pesos individuais, peso do lote e a quantidade de ração consumida no período. A partir dos dados obtidos, pôde-se avaliar a Conversão Alimentar (C.A) das aves, calculada considerando-se o consumo total de ração em cada tratamento (consumo de ração), em relação ao peso total obtido pelo lote (ganho de peso). Avaliou-se também o custo de produção da ração caseira utilizada no experimento, bem como o custo de produção do quilograma de frango vivo, em cada tratamento. Para isso, utilizou-se os valores, expressos em Reais, cotados ao preço do dia 05/06/2009, da seguinte forma:

- Pintinhos de um dia R $\$ 1,45$

- Saca do milho (60 kg) $\mathrm{R} \$ 26,00$

- $\quad$ Saco de farelo de soja (50 kg) $\mathrm{R} \$ 45,00$ 
- Núcleo fase 1 (inicial) $(20 \mathrm{~kg}) \mathrm{R} \$ 52,00$

- Núcleo fase 2 (crescimento) (20kg) $\mathrm{R} \$ 46,00$

- Núcleo fase 3 (terminação) (20kg) R \$35,00

- BACSOL-VT $(1 \mathrm{Kg}) \mathrm{R} \$ 18,00$

Não se considerou nesse calculo, o valor das instalações, energia elétrica, equipamentos ou mão de obra, uma vez que, sendo comum a todos os tratamentos não alteraria o resultado, e também porque nesse modelo de criação, a adaptação de instalações e equipamentos é prática comum e até mesmo recomendada.

Os resultados obtidos foram analisados estatisticamente e comparados pelo teste de Tukey a $5 \%$ de probabilidade de erro $(\mathrm{p}<0,05)$.

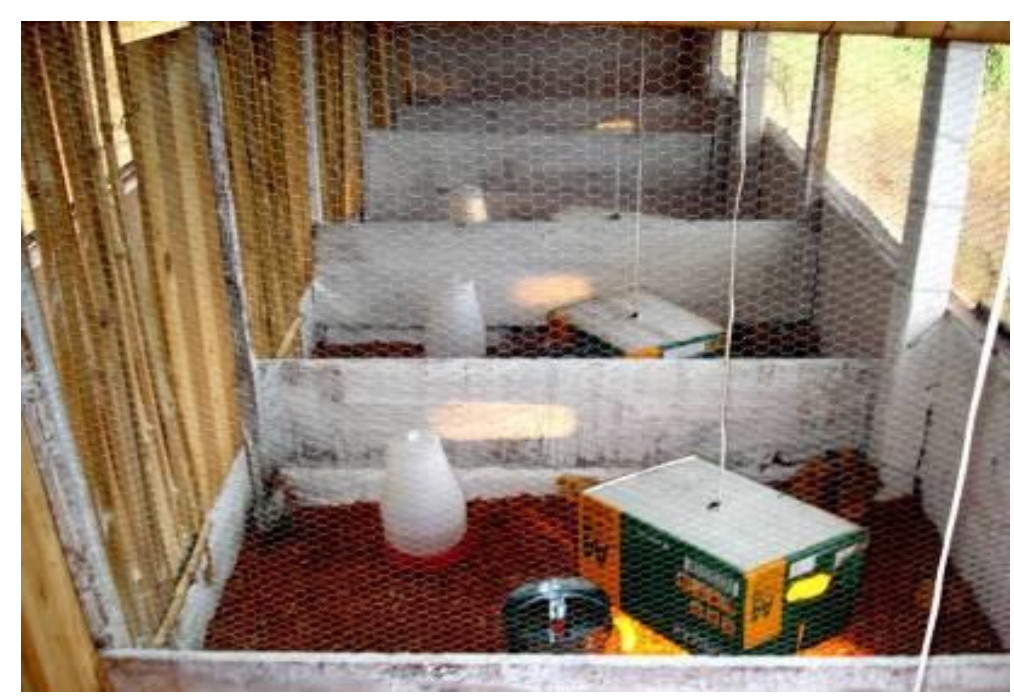

Figura 1: Boxes com iluminação, aquecimento, comedouros e bebedouros prontos para alojar as aves.

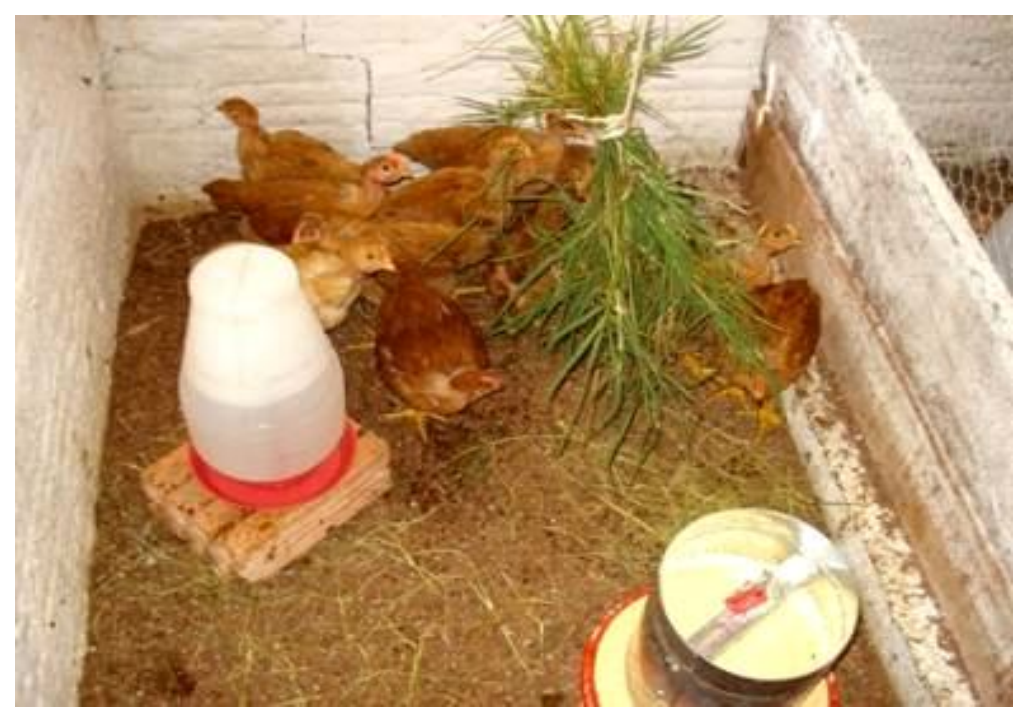

Figura 2: Capim Tifton 85 (Cynodon dactylon) verde, amarrado à altura do pescoço das aves, no centro dos boxes à disposição das aves. 


\section{RESULTADOS E DISCUSSÃO}

As análises estatísticas realizadas referente ao ganho de peso entre tratamentos comparando as diferentes concentrações do probiótico BACSOL-VT na ração de frangos de corte, não apresentaram diferenças significativas $(\mathrm{P}>0,05)$, em nenhuma das pesagens, ao longo do período experimental. Isso mostra que o acréscimo do referido probiótico, nas concentrações em que foram testadas nesse experimento $(0 \mathrm{~g} ; 300 \mathrm{~g}$ e $500 \mathrm{~g}$ por tonelada de ração), não influenciou significativamente o ganho de peso das aves. Os frangos atingiram, aos 84 dias de criação, peso médio de $2,66 \mathrm{Kg} ; 2,67 \mathrm{Kg}$ e 2,63 $\mathrm{Kg}$ de peso vivo, para os tratamentos testemunha (T1); tratamento T2 (BACSOL-VT 0,03\%) e tratamento T3 (BACSOL-VT 0,05\%), respectivamente.

Esses resultados concordam com os resultados obtidos por Lima (1996), que não encontrou efeitos significativos para a adição de probiótico, sobre o desempenho das aves.

Por outro lado, discordam dos resultados obtidos por Mentem (2001) e por Andreatti Filho (2006), que observaram melhora no desenvolvimento dos frangos alimentados com ração acrescida de probiótico.

Deve-se salientar que nesse experimento os frangos foram criados sob boas condições higiênico sanitárias, o que ameniza a ocorrência de microorganismos causadores de desequilíbrio da flora bacteriana intestinal. Em condições higiênicas ruins, observadas normalmente em criações caseiras, o produto poderia eventualmente exercer efeitos positivos, uma vez que, segundo Andreatti Filho (2006), a restauração do equilíbrio da microbiota intestinal do animal é o principal efeito benéfico do uso dos probióticos.

A conversão alimentar calculada apresentou os seguintes valores: Tratamento T1 (Testemunha): Conversão Alimentar (C.A) de 2,14: 1; Tratamento T2 (BACSOL-VT 0,03\%): Conversão Alimentar (C.A) de 2,06:1; Tratamento T3 (BACSOL-VT 0,05\%): Conversão Alimentar (C.A) de 2,05:1.

Pôde-se observar que apesar de não significativa $(\mathrm{P}=0,06)$, há uma tendência de redução (melhora) da C.A com o uso do probiótico. A Conversão Alimentar das aves do Tratamento T2 e do Tratamento T3 foi 3,7\% e 4,2\% melhor que a C.A do tratamento testemunha. Pode-se observar também que esses valores, considerando que são animais semi caipiras, com um ciclo de criação bem superior aos industriais, são baixos, ótimos para esse tipo de criação. Mendes et al. (2004), registraram valores de C.A. para frangos industriais, de 1,83:1, criados e abatidos aos 42 dias. 
A taxa de mortalidade observada durante todo o período experimental foi de $1,4 \%$ considerando-se todo o lote. Esse valor é baixo se comparado às taxas de mortalidade observadas em lotes de frangos industriais, que são consideradas ótimos até 3\%

$\mathrm{O}$ custo do quilograma de ração foi de $\mathrm{R} \$ 0,648 ; \$ 0,653$ e $\mathrm{R} \$ 0,657$ para os tratamentos testemunha, tratamento T2 (BACSOL-VT 0,03\%) e Tratamento T3 (BACSOLVT $0,05 \%$ ), respectivamente. Observa-se que o acréscimo do probiótico elevou em $0,8 \%$ e $1,4 \%$, respectivamente, o custo da ração do tratamento T2 $(0,03 \%)$ e do tratamento T3 $(0,05 \%)$, em relação ao tratamento testemunha. A partir desses valores, estimou-se o custo por quilograma de frango vivo em cada tratamento, bem como o custo total médio de cada frango criado.

Os valores obtidos mostram que, no tratamento testemunha, cada quilograma de frango foi produzido a um custo de $\mathrm{R} \$ 1,39$ (Um real e trinta e nove centavos). Considerando o peso médio dos frangos nesse lote, que foi de 2,66 $\mathrm{kg}$ e o valor do pintinho, de $\mathrm{R} \$ 1,45 \mathrm{a}$ unidade, temos que o valor final de cada frango desse tratamento, foi de $\mathrm{R} \$ 5,15$ (Cinco reais e quinze centavos).

Usando os mesmos critérios, observamos que o quilograma de frango do tratamento $\mathrm{T} 2$ foi de $\mathrm{R} \$ 1,34$ (Um real e trinta e quatro centavos), e o custo final de cada frango desse tratamento, de R \$ 5,03 (Cinco reais e três centavos). Para o tratamento T3, o quilograma do frango teve um custo de $\mathrm{R} \$ 1,31$ (Um real e trinta e um centavos), e o custo final de cada frango desse tratamento foi de $\mathrm{R} \$ 4,89$ ( Quatro reais e oitenta e nove centavos ). Observa-se que o custo do quilograma do frango produzido nos tratamentos T2 $(0,03 \%)$ e tratamento T3 $(0,05 \%)$ foi $3,6 \%$ e $5,8 \%$ menor que no tratamento testemunha (T1), sem o acréscimo do probiótico BACSOL-VT.

Isso ocorreu em função da redução (melhora) observada na conversão alimentar dos lotes que receberam o probiótico, levando os animais a ganhar peso ingerindo menor quantidade de ração.

$\mathrm{O}$ valor médio do frango produzido, considerando todo o lote, foi de $\mathrm{R} \$ 5,02$ (Cinco reais e dois centavos) por unidade. A final do experimento, os frangos vivos foram oferecidos ao preço unitário de $\mathrm{R} \$ 15,00$ (Quinze reais), tendo sido prontamente comercializados, o que evidencia a viabilidade econômica desse modelo de criação de frangos. 


\section{REFERÊNCIAS}

ANDREATTI FILHO, R. L. Saúde aviária e doenças. São Paulo: Roca, 2006. 314p.

ANUALPEC: Anuário da pecuária brasileira. São Paulo: FNP, 2008. 380p.

ÁVILA, F.A.et al. Escherichia coli isolated from calves with diarrhea in the northern region of state of São Paulo, Brazil. Ars Vet., v.4, p.285-289, 1998.

DEMATTÊ FILHO, L.C., MENDES, C.M.I. Viabilidade técnica e econômica na criação alternativa de frangos. In: CONFERÊNCIA APINCO 2001 DE CIÊNCIA E TECNOLOGIA AVÍCOLA, Campinas,2001. Anais...Campinas: FACTA, p.255-266, 2001.

FIGUEIREDO, E.A P. et al. Diferentes denominações e classificação brasileira de produção alternativa de frangos. In: CONFERÊNCIA APINCO 2001 DE CIÊNCIA E TECNOLOGIA AVÍCOLA, Campinas,2001. Anais...Campinas:FACTA, p.209-222, 2001.

FIGUEIREDO, E.A.P.; ÁVILA, V.S. Produção agroecológica de frangos de corte e galinhas de postura. Concórdia: Embrapa Suínos e Aves, 2001. 185p.

LANA, G.R.Q. Criação de galinha caipira. In: SEMANA DE ZOOTECNIA DA UFRPE, Recife, 2001. 34p.

LIMA, A.C.F. Efeito do uso de probiótico sobre o desempenho e atividade de enzimas digestivas de frangos de corte. 1996. 70p. Dissertação (Mestrado em Zootecnia) Universidade Estadual Paulista. Jaboticabal.

MENDES, A. A.et al. Produção de frangos de corte. Campinas: FACTA, 2004. 356p.

MENTEN, J.F.M. Aditivos alternativos na nutrição de aves: probióticos e prebióticos. In: Reunião Anual da Sociedade Brasileira de Zootecnia, 38., 2001, Piracicaba. Anais...Piracicaba, SBZ, 2001, p.141-157.

MUNIZ, P.F. O frango classificado como alternativa aos pequenos e médios produtores. In: CONFERÊNCIA APINCO 2001 DE CIÊNCIA E TECNOLOGIA AVÍCOLA, CAMPINAS,2001. Anais... Campinas:FACTA,2001.p.267 - 272. 